СТАТЬИ

УДК 504.064.2

ОЦЕНКА УРОВНЕЙ ЗАГРЯЗНЕНИЯ ТЕРРИТОРИИ РЕСПУБЛИКИ БЕЛАРУСЬ АТМОСФЕРНЫМИ ВЫПАДЕНИЯМИ ТЯЖЕЛЫХ МЕТАЛЛОВ С ИСПОЛЬЗОВАНИЕМ БРИОИНДИКАЦИИ

\author{
Алексеенок Ю.В., Вергель К.Н., Юшин Н.С.
}

Объединенный институт ядерных исследований, Дубна, е-тail: beataa@gmail.com, verkn@mail.ru,ynik62@mail.ru

Загрязнение атмосферного воздуха оказывает негативное воздействие как на здоровье человека, так и на состояние животного и растительного мира, поэтому контроль качества атмосферного воздуха является важной составляющей мониторинга окружающей среды. Наряду со стандартными методами мониторинга загрязнения воздуха в последние двадцать пять лет широкое распространение во многих странах Европы получил метод биомониторинга атмосферных выпадений различных загрязняющих веществ с использованием мхов. В Беларуси подобные исследования на регулярной основе начались с 2005 г. В данной работе на основе результатов, полученных с использованием мхов-биомониторов, произведена оценка уровней загрязнения тяжелыми металлами и полуметаллами территории Республики Беларусь в период с 2005 по 2015 г. Были рассчитаны коэффициенты загрязнения для отдельных элементов, а также суммарные показатели загрязнения территорий шести административных областей, учитывающие элементы, которые относятся к 1 , 2 и 3 классам опасности. Был оценен коэффициент биологического поглощения элементов для используемых видов мха, определены фоновые концентрации элементов во мхах для Беларуси. Результаты расчетов показали, что наблюдается слабое загрязнение территории никелем. Интегрированная оценка выявила области с высоким, средним и низким уровнем загрязнения и показала локализацию загрязненных территорий. За десятилетний период исследования площади территорий со средним уровнем загрязнения снизились почти в два раза, а территории с высоким уровнем загрязнения в 2015 г. уже отсутствовали. Полученные временные тренды хорошо отражают сокращение количества выбросов в атмосферный воздух от местных источников за исследуемый период.

Ключевые слова: бриоиндикация, Pleurozium schreberi, тяжелые металлы, аэрозоли, нейтронный активационный анализ, уровни загрязнения

\title{
ASSESSMENT OF THE POLLUTION LEVELS OF THE TERRITORY OF THE REPUBLIC OF BELARUS BY HEAVY METALS ATMOSPHERIC DEPOSITION USING BRYOINDICATION
}

\author{
Aleksiayenak Yu.V., Vergel K.N., Yushin N.S. \\ Joint Institute for Nuclear Research,Dubna, e-mail: beataa@gmail.com, \\ verkn@mail.ru,ynik_62@mail.ru
}

\begin{abstract}
Ambient air pollution has a negative impact on both human health and the state of flora and fauna, therefore, air quality control is an important component of environmental monitoring. Along with the standard methods for monitoring air pollution in the last twenty-five years, the method of biomonitoring atmospheric deposition of various pollutants using mosses has become widespread in many European countries. In Belarus, such studies have begun regularly since 2005 . In this work, based on the results obtained using mosses-biomonitors, the assessment of the levels of pollution by heavy metals and semimetals of the territory of the Republic of Belarus in the period from 2005 to 2015 is made. The pollution factors were calculated for individual elements, as well as the total indicators of pollution of the territories of six administrative regions, taking into account the elements that belong to 1, 2 and 3 hazard classes. The coefficient of biological absorption of elements for the species of moss used was estimated, the background concentrations of elements in mosses for Belarus were determined. The calculation results showed that there is slight pollution of the territory with nickel. The integrated assessment identified areas with high, medium and low levels of pollution and showed the localization of contaminated areas. Over the ten years of research, the areas of territories with an average level of pollution decreased by almost two times, and areas with a high level of pollution in 2015 were already absent. The obtained time trends well reflect the reduction in the amount of emissions into the atmospheric air from local sources over the period under study.
\end{abstract}

Keywords: bryoindication, Pleurozium schreberi, heavy metals, aerosols, neutron activation analysis, pollution levels

Загрязнение атмосферного воздуха - это глобальная проблема, которая оказывает негативное воздействие на людей, животных и растения. В наши дни особое внимание уделяется таким загрязнителям, как оксиды серы, азота и углерода, стойкие органические загрязнители (СО3), тяжелые металлы (TM) и взвешенные частицы. Природные источники этих веществ - лесные пожары, извержения вулканов, гейзеры, биоразложение и океаны. Большинство же тяжелых металлов, а также сера, азот и оксиды углерода имеют антропогенное происхождение. Значительная часть выбросов загрязняющих веществ остается в непосредственной близости от источника, при этом некоторые из них можно обнаружить на достаточно большом расстоянии от источника. Пробле- 
ма трансграничного загрязнения воздуха стоит довольно остро перед всеми странами, так как неблагополучная экологическая обстановка в одном регионе может отрицательно воздействовать на территории без своих источников загрязняющих веществ. Так, например, для окружающей среды Арктики представляют угрозу ртуть и СО3, которые поступают на территорию извне, в основном из южных промышленных районов Европы и других континентов из-за ветров преимущественно северного направления [1].

В связи с этим в 1979 г. Европейской экономической комиссией Организации Объединенных Наций (ЕЭК ООН) была принята Конвенция о трансграничном загрязнении воздуха на большие расстояния. А в 1998 г. 36 стран подписали Орхусский протокол к Конвенции по дальнему трансграничному переносу воздушных загрязнений тяжелыми металлами от 1979 г.

В ряде европейских стран потребность в изучении последствий воздействия тяжелых металлов на окружающую среду привела к созданию национальных и международных программ по биомониторингу атмосферных выпадений тяжелых металлов. В рамках Международной совместной программы по растительности (ICP Vegetation) «Атмосферные выпадения тяжелых металлов в Европе - оценки на основе анализа мхов-биомониторов» с периодичностью в пять лет под эгидой ООН издается Европейский атлас атмосферных выпадений ТМ. Цель этой программы - качественно и количественно охарактеризовать распределение региональных атмосферных выпадений в Европе, выделить местоположение важных источников загрязнения ТМ и дать ретроспективную картину сравнения с такими же исследованиями, повторяющимися каждые пять лет. Ближайшей целью деятельности этой Комиссии является сбор информации по атмосферным загрязнениям тяжелыми металлами в 2020-2021 гг. в соответствии с Орхусским протоколом.

Европейские исследования мхов по этой программе проводятся каждые пять лет с 1990 г., последний раз оно было проведено в 2015 г. с участием 34 стран [2]. В литературе представлены данные о концентрации двенадцати металлов (Al, $\mathrm{As}, \mathrm{Cd}, \mathrm{Cr}$, $\mathrm{Cu}, \mathrm{Fe}, \mathrm{Hg}, \mathrm{Ni}, \mathrm{Pb}, \mathrm{Sb}, \mathrm{V}, \mathrm{Zn}$ ) в естественно растущих мхах. Для отбора рекомендуются плеврокарповые мхи, такие как Hylocomium splendens, Pleurozium schreberi, Hypnum cupressiforme, Pseudoscleropodium purum.
В рамках этой программы исследования выпадений тяжелых металлов на территории Республики Беларусь регулярно начали проводиться с 2005 г. [3].

Целью и задачами исследования были:

- оценить уровни загрязнения территории на основе расчетов комплексных показателей загрязнения территории и коэффициентов загрязнения для исследуемых элементов;

- определить фоновые значения элементов для страны;

- сравнить полученные данные со стандартными методами оценки антропогенного воздействия.

\section{Материалы и методы исследования}

На исследуемой территории были отобраны образцы мха вида Pleurozium schreberi, широко используемого в целях биомониторинга, в период с июля по сентябрь в 2005 и 2015 гг. в разных областях страны. Отбор проб на одних и тех же площадках в 2005 и 2015 гг. осуществлялся в Минской области, где в 2005 г. были выявлены участки с большим уровнем загрязнения в сравнении с остальной территорией. С учетом местных особенностей для территории Беларуси была разработана мониторинговая сеть и за период исследования было отобрано порядка 200 образцов (рис. 1).

\section{Исследуемая территория}

Республика Беларусь находится на Восточно-Европейской равнине, для нее характерен континентальный климат с достаточным увлажнением и преобладающим западным переносом воздушных масс. Образцы отбирались в сосняках мшистых, орляковых и черничных на дерново-подзолистых почвах. В годы пробоотбора количество осадков по областям существенно не менялось и находилось в диапазоне от 520 до 710 мм в год в зависимости от области. Количество пожаров по исследуемым областям также изменялось незначительно.

Согласно официальным данным основными источниками выбросов тяжелых металлов в атмосферный воздух на территории Беларуси являются: производство чугуна и стали, стационарное сжигание топлива в промышленности, черная металлургия, нефтепереработка, мобильные источники, химическая промышленность [4]. Около $50 \%$ промышленных предприятий республики находятся в г. Минске и Минской области. Меньше всего предприятий зарегистрировано в Витебской и Гродненской областях 9\%. 


\section{Пробоотбор}

Для анализа отбираются зеленые и зелено-коричневые сегменты мха, которые примерно соответствуют возрасту растения 3-5 лет. Образцы отбирались в отдалении от городов и крупных промышленных центров, минимум 300 м от дорог. С одного участка собирался образец, состоящий из пяти подобразцов, отобранных по методу конверта.

\section{Анализ}

Аналитические исследования проводились в Лаборатории нейтронной физики (ЛНФ) Объединенного института ядерных исследований (ОИЯИ) (Дубна, Россия). Элементный состав образцов определяли с использованием инструментального нейтронного активационного анализа (ИНАА) на реакторе ИБР-2 ЛНФ и атомной абсорбционной спектрометрии (AАC). С помощью ИНАА во мхах-биоиндикаторах было определено 27 химических элементов: Al, As, $\mathrm{Ba}, \mathrm{Br}, \mathrm{Ca}, \mathrm{Cl}, \mathrm{Co}, \mathrm{Cs}, \mathrm{Fe}, \mathrm{Hf}, \mathrm{K}, \mathrm{La}, \mathrm{Mg}$, $\mathrm{Mn}, \mathrm{Na}, \mathrm{Ni}, \mathrm{Rb}, \mathrm{Sb}, \mathrm{Sc}, \mathrm{Se}, \mathrm{Sm}, \mathrm{Sr}, \mathrm{Th}, \mathrm{U}, \mathrm{V}$, $\mathrm{W}, \mathrm{Zn}$. АAC применялась для определения $\mathrm{Pb}, \mathrm{Cd}$ и $\mathrm{Cu}$. В специально оборудованной химической лаборатории осуществлялась подготовка образцов к облучению. Образцы тщательно очищались от хвои, листьев и т.д., а затем сушились при температуре $40^{\circ} \mathrm{C}$ до постоянного веса. Затем мох прессовали в таблетки весом $\sim 0,3$ г, которые упаковывались в полиэтиленовые пакеты для короткого облучения и в алюминиевую фольгу для длительного облучения. Более подробно анализ описан в работе [3].

Контроль качества анализа осуществлялся с использованием сертифицированных эталонов: IAEA 336 (лишайник, МАГАТЭ), IAEA 433 (морские отложения, МАГАТЭ), SRM 1575 (иглы сосны, NIST), SRM 2710 (почва, NIST), SRM 2711 (почва, NIST). Эталоны облучались вместе с исследуемыми образцами в одинаковых условиях.

Концентрации $\mathrm{Cd}, \mathrm{Cu}$ и $\mathrm{Pb}$ в образцах мха определяли с помощью атомно-абсорбционного спектрометра iCE 3300 AAC c электротермической (графитовой) печью атомизацией (Thermo Fisher Scientic, Waltham, MA, USA). Калибровочные растворы готовили из исходного раствора массой 1 г/л (стандартный раствор АAC; Merck, DE). Более подробное описание анализа можно найти в работе Швецовой [5]. Контроль качества проводился с использованием сертифицированных стандартных образцов NIST - SRM 1570a (листья шпината) и SRM 1575a (сосновые иглы).

\section{Pacчеть}

Были вычислены коэффициенты биологического поглощения $\left(\mathrm{K}_{6}\right)$ различных элементов - это отношение содержания элемента в золе растения к содержанию этого же элемента в почвах или горных породах [6]. Этот коэффициент позволяет определить кумулятивные способности растений и оценить уровни накопления тех или иных элементов.

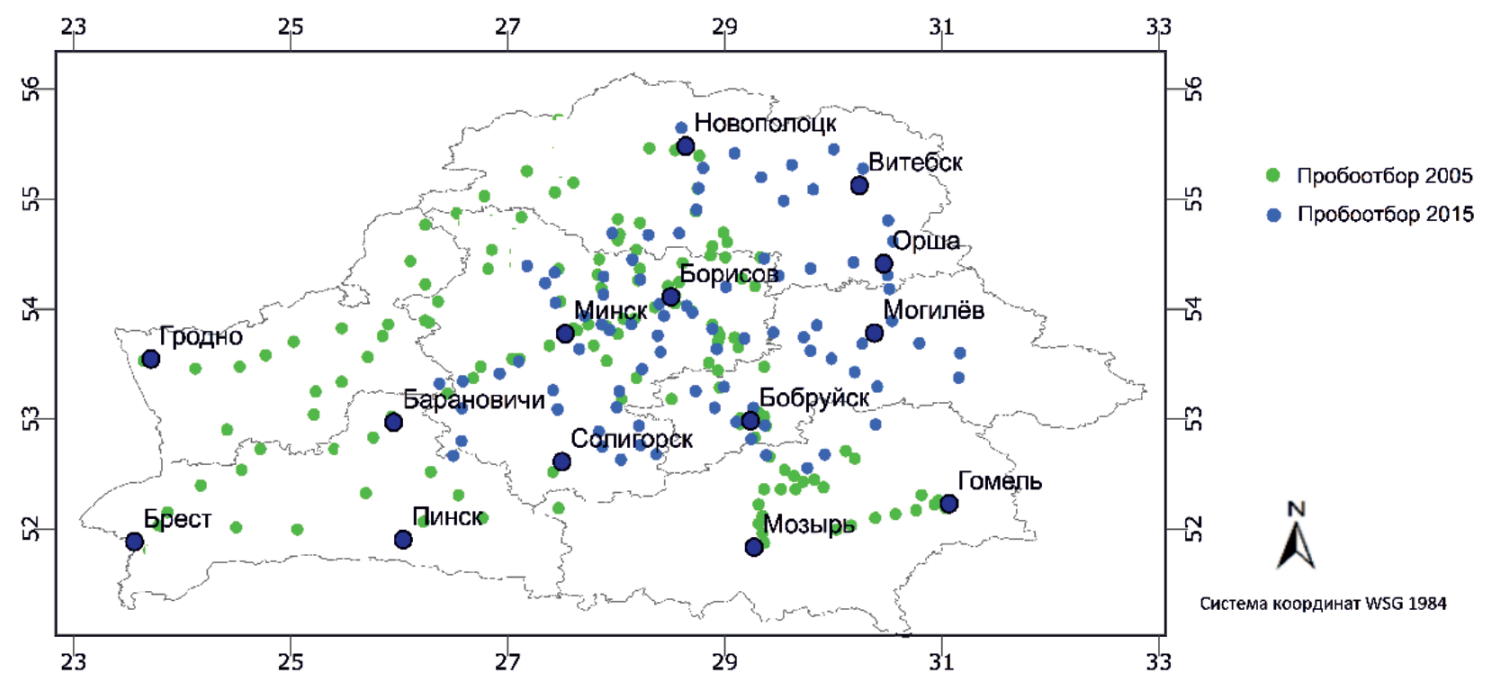

Рис. 1. Схема пробоотбора мхов-биоиндикаторов в 2005 и 2015 г2. 
Критерии оценки загрязнения по разным показателям [12]

\begin{tabular}{|l|c|c|}
\hline \multicolumn{1}{|c|}{ Уровень загрязнения } & \multicolumn{2}{c|}{ Химические элементы } \\
\cline { 2 - 3 } & $\mathrm{CF}$ & $\mathrm{K} 3$ \\
\hline Минимальный (возможное загрязнение) & $1-2$ & $8-16$ \\
\hline Низкий (слабый) & $2-3,5$ & $16-32$ \\
\hline Средний (умеренный) & $3,5-8$ & $32-128$ \\
\hline Высокий (сильный) & $8-27$ & $>128$ \\
\hline Очень высокий (чрезвычайно сильный) & $>27$ & \\
\hline
\end{tabular}

Для оценки геоэкологического состояния территории рассчитывались коэффициенты загрязнения (CF - contamination factor) paссматриваемых элементов для наземных мхов [7], в русскоязычной литературе аналогичный по расчетам показатель используется для оценки содержания элементов в почвах и называется коэффициентом концентрации:

$$
\mathrm{CF}=\mathrm{C}_{\text {эл }} / \mathrm{C}_{\text {фон }},
$$

где $\mathrm{C}_{э}$ - концентрация элемента, a $\mathrm{C}_{\text {фон }}$ фоновая концентрация соответствующего элемента. Значение фоновых концентраций элементов рассчитывалось как среднее значение по выборке за исключением минимально аномальных значений [8].

Коэффициент загрязнения рассчитывался для каждого элемента. Полученные данные позволяют определить уровни загрязнения территории каждым элементом, начиная от нетронутых, заканчивая сильно загрязненными (табл. 1).

Для каждой точки пробоотбора были рассчитаны суммарные показатели загрязнения воздуха $\left(\mathrm{K}_{3}\right)$ экологически опасными химическими элементами, относящимися к нескольким классам опасности: чрезвычайно опасные - 1 класс $(\mathrm{Pb}, \mathrm{Cd}, \mathrm{Se}, \mathrm{Ba})$, умеренно опасные - 2 класс $(\mathrm{Cu}, \mathrm{Ni}, \mathrm{Co}, \mathrm{Sb}$, $\mathrm{Br}, \mathrm{As}, \mathrm{Mn}, \mathrm{V}, \mathrm{Fe}$ ) и малоопасные - 3 класс опасности (W, Sr, Zn) [9]. Расчеты производились по модифицированной формуле, взятой в работах $[10 ; 11]$, и с более строгими критериями [12]. Показатели (Кз) были рассчитаны по всем вместе взятым экологически опасным элементам по формуле

$$
\mathrm{K}_{3}=\Sigma \mathrm{CF}-(\mathrm{n}-1),
$$

где $n-$ количество элементов, коэффициенты концентраций которых суммируются. При этом в расчетах участвовали CF только тех элементов, для которых факт превышения фонового содержания установлен статистически надежно. Это были значения CF, которые превышали минимально аномальное значение содержания элемента во мхах $-\mathrm{CF}_{\text {мин }}$.

$$
\mathrm{CF}_{\text {мин }}=\varepsilon_{\text {погр }} 3 / \mathrm{Jn}_{\mathrm{n}},
$$

где $\varepsilon_{\text {погр }}-$ погрешность опробования и анализа, которая определяется как стандартное отклонение по выборке, умноженное на коэффициент Стьюдента для этого количества вариантов, а $n$ - количество точек пробоотбора.

\section{Результаты исследования и их обсуждение}

По коэффициентам биологического поглощения видно, что активнее всего мхи захватывают $\mathrm{Br}, \mathrm{Cd}, \mathrm{Cl}, \mathrm{K}, \mathrm{Mn}, \mathrm{Se}, \mathrm{W}, \mathrm{Zn}$ (табл. 2). Коэффициенты биологического накопления меньше 10 , но больше единицы у $\mathrm{Co}, \mathrm{Cs}, \mathrm{Hf}, \mathrm{Pb}, \mathrm{Rb}, \mathrm{Sb}, \mathrm{Sr}$ и др. Большинство элементов этой группы играют важную роль в физиологии растений. Мхи также активно поглощают токсичные As, $\mathrm{Se}$ и др. Средний коэффициент биологического накопления для растений, рассчитанный Перельманом, показал, что интенсивное накопление характерно для таких элементов, как $\mathrm{P}, \mathrm{S}, \mathrm{Cl}, \mathrm{Br}$, I, затем идут - $\mathrm{Ca}, \mathrm{Na}, \mathrm{K}, \mathrm{Mg}, \mathrm{Sr}, \mathrm{Zn}, \mathrm{B}$, Se. Средний биологический захват характерен для $\mathrm{Mn}, \mathrm{F}, \mathrm{Ba}, \mathrm{Ni}, \mathrm{Cu}, \mathrm{Ga}, \mathrm{Co}, \mathrm{Pb}, \mathrm{Sn}, \mathrm{As}, \mathrm{Mo}$, $\mathrm{Hg}, \mathrm{Ag}, \mathrm{Ra}$; слабый - для $\mathrm{Si}, \mathrm{Al}, \mathrm{Fe}, \mathrm{Rb}, \mathrm{V}$, $\mathrm{Cr}, \mathrm{Th}, \mathrm{Sc}, \mathrm{Be}, \mathrm{Cs}, \mathrm{Ta}, \mathrm{U}, \mathrm{W}, \mathrm{Sb}, \mathrm{Cd}$ [6]. Следует отметить, что один и тот же элемент в зависимости от местообитания растения будет иметь разный коэффициент биологического поглощения. Из полученных данных видно, что мхи, как и все растения, активно накапливают биофильные элементы с активной миграцией в водных растворах. При этом малоподвижные элементы, такие как $\mathrm{Al}, \mathrm{Cr}, \mathrm{Hf}, \mathrm{La}, \mathrm{Sc}, \mathrm{Sm}, \mathrm{Tb}, \mathrm{Th}, \mathrm{W}$, $\mathrm{Zn}$ и др., также накапливаются во мхах, что может свидетельствовать об их ветровом пути поступления и показывает особенности строения мхов, которые позволяют задерживать пылевые частицы. 
Таблица 2

Интенсивность биологического поглощения металлов (Кб) P. Shreberi

\begin{tabular}{|c|c|l|c|}
\hline Группа & Ср. зн. Кб & \multicolumn{1}{|c|}{ Группа } & Металлы и металлоиды \\
\hline \multirow{2}{*}{1} & $\mathrm{~K} \mathrm{cp}<0,1$ & Малого биологического захвата & - \\
\cline { 2 - 4 } & $\mathrm{K} \mathrm{cp}<1$ & Среднего биологического захвата & $\mathrm{Na}, \mathrm{Al}, \mathrm{Sc}, \mathrm{V}, \mathrm{Fe}, \mathrm{Ce}, \mathrm{Sm}, \mathrm{Th}, \mathrm{U}$ \\
\hline 2 & \multirow{2}{*}{ К ср $>1$} & Интенсивного биологического накопления & $\begin{array}{c}\mathrm{Mg}, \mathrm{Ca}, \mathrm{Cr}, \mathrm{Co}, \mathrm{Cu}, \mathrm{As}, \mathrm{Rb}, \mathrm{Sr}, \mathrm{Sb}, \\
\mathrm{Cs}, \mathrm{Ba}, \mathrm{La}, \mathrm{Hf}, \mathrm{Pb}\end{array}$ \\
\cline { 2 - 4 } & $\mathrm{K} \mathrm{cp}>10$ & Сильного биологического накопления & $\mathrm{Cl}, \mathrm{K}, \mathrm{Mn}, \mathrm{Zn}, \mathrm{Se}, \mathrm{Br}, \mathrm{W}, \mathrm{Cd}$ \\
\hline
\end{tabular}

Таблица 3

Расчетные фоновые значения для некоторых элементов (мг/кг)

\begin{tabular}{|c|c|c|c|c|c|c|c|c|c|c|c|c|}
\hline Элементы & $\mathrm{As}$ & $\mathrm{Cd}$ & $\mathrm{Cr}$ & $\mathrm{Co}$ & $\mathrm{Cu}$ & $\mathrm{Fe}$ & $\mathrm{Mn}$ & $\mathrm{Ni}$ & $\mathrm{Pb}$ & $\mathrm{Sb}$ & $\mathrm{V}$ & $\mathrm{Zn}$ \\
\hline Фоновые значения, мг/кг & 0,16 & 0,30 & 2,1 & 0,260 & 5,0 & 436 & 375 & 1,02 & 2,67 & 0,10 & 1,26 & 35 \\
\hline
\end{tabular}

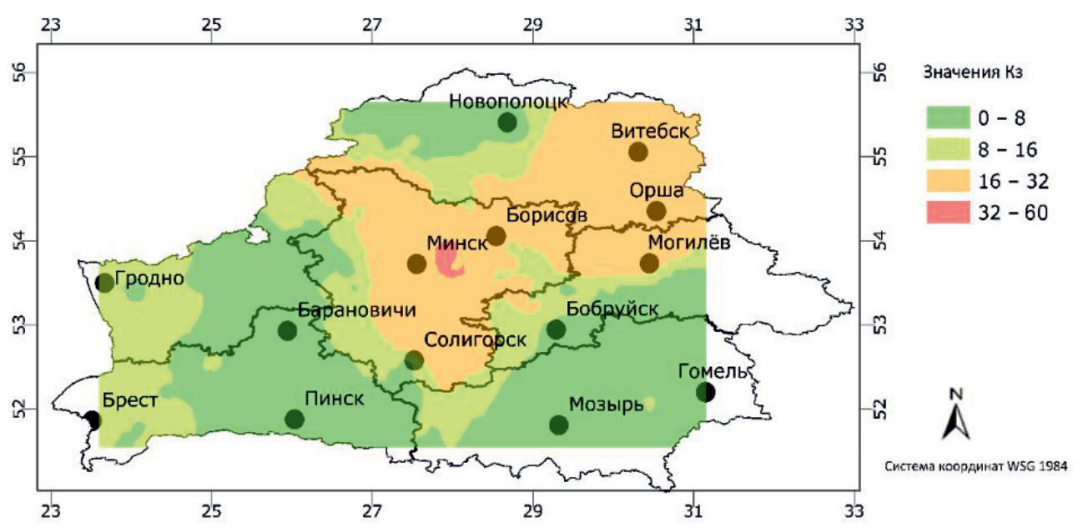

Рис. 2. Географическое распределение показателя Кз в исследованиях 20052.

По результатам фоновых значений видно (табл. 3), что для большинства элементов, за исключением хрома, железа, свинца и сурьмы, значения совпадают в пределах погрешности с медианными значениями по Норвегии [3], которая в ряде работ по биомониторингу рассматривается как фоновая территория.

Результаты исследования по загрязнению страны отдельными элементами (CF) показали, что присутствует слабое загрязнение территории никелем. Официально основными источниками выбросов никеля являются предприятия нефтепереработки (более $60 \%$ выбросов), стационарное сжигание топлива, производство тепла и электричества, а также передвижные источники [4]. Возможное загрязнение наблюдается для 18 элементов как природного, так и антропогенного происхождения $(\mathrm{Mg}, \mathrm{K}, \mathrm{Cl}$, $\mathrm{Sc}, \mathrm{Mn}, \mathrm{Cu}, \mathrm{As}, \mathrm{Se}, \mathrm{Br}, \mathrm{Rb}, \mathrm{Sr}, \mathrm{Ba}, \mathrm{La}, \mathrm{Sm}, \mathrm{Hf}$, $\mathrm{Pb})$; по оставшимся элементам ( $\mathrm{Na}, \mathrm{Al}, \mathrm{Ca}$, $\mathrm{V}, \mathrm{Fe}, \mathrm{Co}, \mathrm{Zn}, \mathrm{Cd}, \mathrm{Sb}, \mathrm{Cs}, \mathrm{W}, \mathrm{Th}, \mathrm{U})$ загрязнение отсутствует $(\mathrm{CF}<1)$.
Использование интегрированного коэффициента загрязнения (Кз) помогло ранжировать территорию по уровням загрязнения, для отслеживания временной динамики показатель рассчитывался для площадок пробоотбора 2005 и 2015 гг. Анализ территории с помощью суммарного показателя загрязнения воздуха (Кз) показал, что в 2005 г. в Минской области высокий уровень загрязнения наблюдался только в четырех местах пробоотбора (7\% от всех исследуемых мест области). Эти площадки располагаются рядом с городами Борисов и Минск. Умеренный или средний уровень загрязнения характерен для $31 \%$ мест пробоотбора. На $15 \%$ территории наблюдается низкий уровень загрязнения, а $46 \%$ исследуемой территории не относится к загрязненной (рис. 2). В 2015 г. ситуация изменилась в лучшую сторону: высоких уровней загрязнения в Минской области не наблюдалось, средний уровень составил всего $8 \%$. Низкий уровень загрязнения определен в $15 \%$ всех мест пробоотбора, а в $77 \%$ мест загрязнение отсутствует (рис. 3). 
В других областях ситуация похожая и не показала значительных изменений с течением времени. Так, в Витебской области $84 \%$ исследуемой территории относится к чистой, $11 \%$ - территория с низким уровнем загрязнения и лишь 5\% территории со средним уровнем загрязнения. В Могилевской области $5 \%$ территории относится к среднему уровню загрязнения, 19\% - низкий уровень загрязнения и в 76\% - загрязнение отсутствует. В Гродненской области наблюдается схожая ситуация, и на $5 \%$ территории выявлен средний уровень загрязнения, на $17 \%$ - низкий и $78 \%$ - это чистая территория. В Гомельской области средний уровень загрязнения наблюдается только в $3 \%$ исследуемых площадок, $9 \%$ это территория с низким уровнем, чистая территория составляет $88 \%$. В Брестской области в отличие от других областей нет среднего уровня загрязнения, и там 26\% мест - это территория с низким уровнем загрязнения, а 78\% - относится к чистой территории.
Согласно официальным данным максимальные выбросы загрязняющих веществ по Беларуси фиксируются на территории Минской области, что ожидаемо, так как там находится 51 \% от всех предприятий страны. В Брестской, Гомельской, Гродненской, Могилевской и Витебской областях находится $11,10,10,8$ и 9\% всей промышленности соответственно. Динамика выбросов загрязняющих веществ в атмосферу показывает, что в 2009 г. по всем областям наблюдались максимальные выбросы за исследуемый период (рис. 4). А в 2013 и 2014 гг. выбросы снизились по сравнению с 2005 г.

Исследования белорусских коллег показали [13, 14], что уровень антропогенной нагрузки на среду жизнедеятельности населения Республики Беларусь c 2001 по 2015 г. имеет тенденцию к снижению. Высокие уровни антропогенной нагрузки наблюдаются в Минской и Гомельской областях, повышенные - в Витебской и Брестской, а средние - в Гродненской и Могилевской областях.

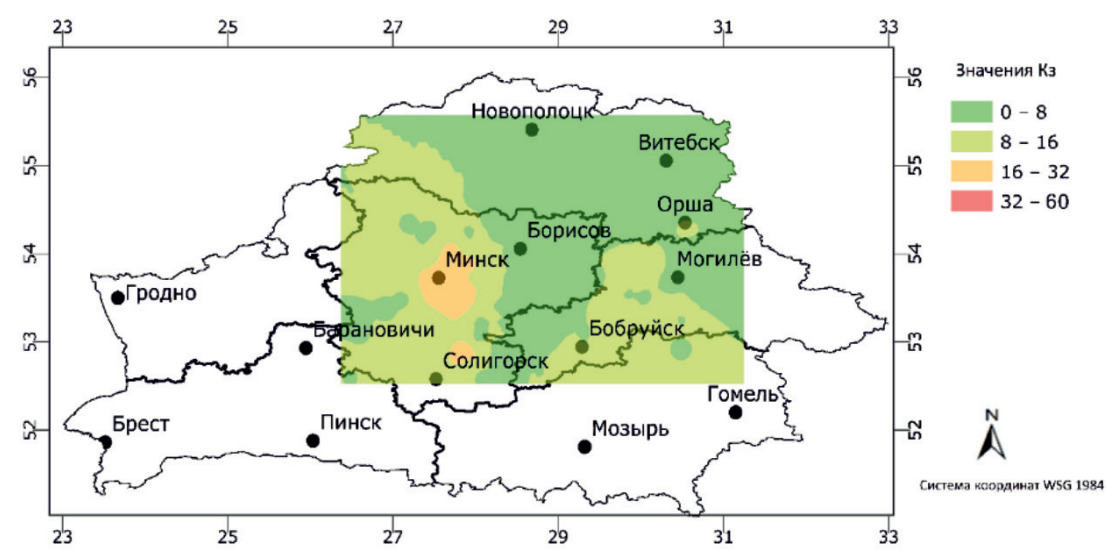

Рис. 3. Географическое распределение показателя Кз в исследованиях 20152.

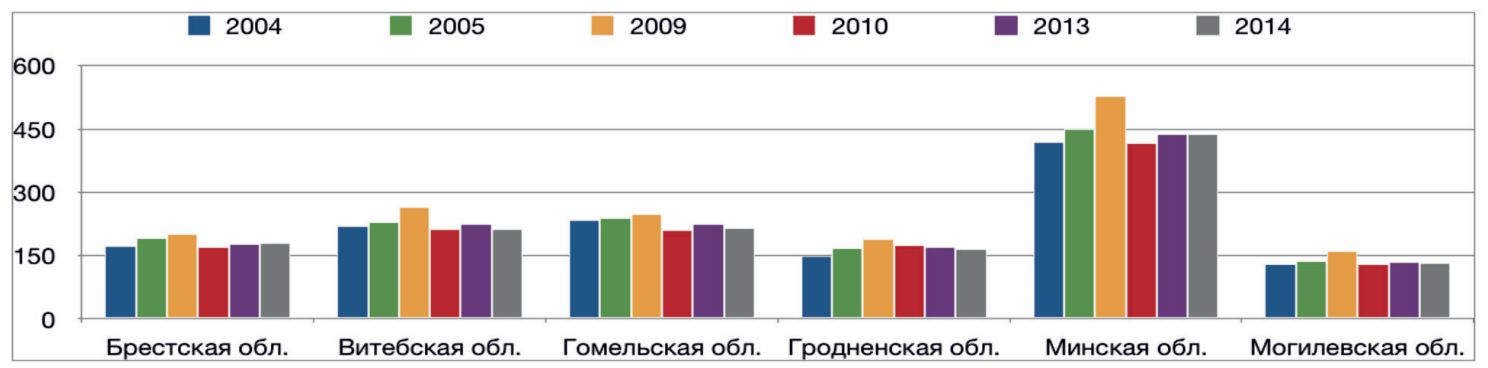

Рис. 4. Валовые выбросы загрязняющих вещееств в атмосферу от стационарных и мобильных источников на территории Беларуси в разные годы (mblc. m) 


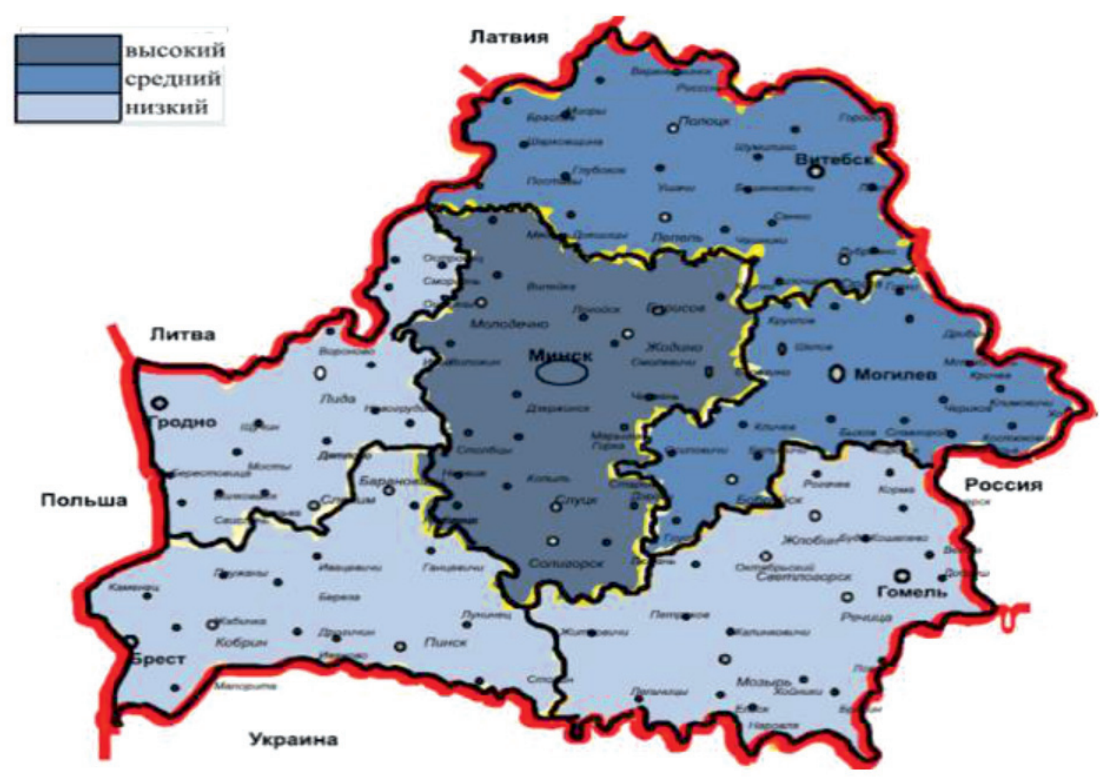

Рис. 5. Среднегодовой уровень антропогенной нагрузки (высокий, средний, низкий) на атмосферный воздух по областям Республики Беларусь в период с 2004 по 2010 г. [15]

По другим данным в период с 2004 по 2010 г. наблюдалось усиление антропогенной нагрузки на атмосферный воздух по сравнению с 1990-ми гг. Согласно расчетам Матковской [15] уровни антропогенной нагрузки на атмосферный воздух отличаются по разным периодам времени для каждой из областей Республики Беларусь. Наиболее высокому воздействию подвергается Минская область и г. Минск. А в группу с самым низким уровнем негативного воздействия на атмосферный воздух попадают Гомельская, Брестская и Гродненская области. Распределение уровней антропогенной нагрузки на атмосферный воздух по разным областям представлено на рис. 5. Данные за 2015 г. отсутствуют.

\section{Заключение}

По значениям коэффициента биологического накопления хорошо видно, что исследуемые мхи интенсивно накапливают экологически опасные элементы, загрязняющие атмосферный воздух. Из тридцати определенных элементов присутствует слабое загрязнение территории только никелем. Данные, полученные с использованием мхов-биоиндикаторов, отражают тенденции по снижению выбросов загрязняющих веществ в атмосферный воздух. Оценка уровней загрязнения областей страны тяжелыми металлами совпадает со стандартными расчетами оценок антропогенного загрязнения атмосферного воздуха для Минской и Брестской областей. Для остальных областей уровни загрязнения отличаются, так как в стандартной оценке учитываются суммарные выбросы вредных веществ (твердые частицы, диоксид серы, диоксид и оксид азота, углеводороды, неметановые летучие органические соединения и тяжелые металлы). В каждой административной области территория со средним уровнем загрязнения составляет от 5-8\% исследуемой территории, низкий уровень наблюдается на $15-$ $26 \%$ исследуемой территории. Оставшаяся часть страны относится к незагрязненным областям. За десять лет наблюдается снижение загрязнения территории Минской области тяжелыми металлами в два раза.

\section{Список литературы / References}

1. Koivurova T., Kankaanpää P., Stepien A. Innovative Environmental Protection: Lessons from the Arctic. Journal of Environmental Law. 2015. Vol. 27. Issue 2. P. 285-311. DOI: 10.1093/jel/equ037.

2. Frontasyeva M.V., Harmens H., Uzhinskiy A., Chaligava O. and participants of the moss survey (2020). Mosses as biomonitors of air pollution: 2015/2016 survey on heavy metals, nitrogen and POPs in Europe and beyond. Report of the ICP Vegetation Moss Survey Coordination Centre, Dubna: JINR, 2020. $136 \mathrm{p}$.

3. Aleksiayenak Y., Frontasyeva M. A ten-year biomonitoring study of atmospheric deposition of trace elements at the territory of the Republic of Belarus. Ecological Chemistry and Engineering S. 2019. Vol. 26. № 3. P. 455-464. DOI: 10.1515/ eces-2019-0034.

4. Охрана окружающей среды в Республике Беларусь. Статистический сборник. Минск, 2015. 255 с. 
Environmental protection in the Republic of Belarus. Statistical compilation. Minsk, 2015. 255 p. (in Russian).

5. Швецова М.С., Каманина И.З., Мададзада А.И., Нехорошков П.С., Юшин Н.С., Зиньковская И.И., Павлов С.С., Фронтасьева М.В. Определение следовых элементов $(\mathrm{Cu}$ $\mathrm{Sb}, \mathrm{Pb}, \mathrm{V}, \mathrm{Zn}$ ) на территории рекреационных зон Москвы с помощью техники «Мох в мешках»// Успехи современного естествознания. 2020. № 8. C. 74-82. DOI: 10.17513/ use. 37461 .

Shvetsova M.S., Kamanina I.Z., Madadzada A.I., Nekhoroshkov P.S., Yushin N.S., Zinkovskaya I.I., Pavlov S.S., Frontaseva M.V. Determination of trace elements $(\mathrm{Cu}, \mathrm{Sb}, \mathrm{Pb}, \mathrm{V}, \mathrm{Zn})$ in the territory of recreation zones of Moscow using the «Moss bags») technique // Advances in current natural sciences. 2020 № 8. P. 74-82. DOI: 10.17513/use.37461.

6. Добровольский В.В. Основы биогеохимии: учебник. М.: Центр Академия, 2003. 400 c.

Dobrovolsky V.V. Basics of biogeochemistry. M.: Centre Academy, 2003. 400 p. (in Russian).

7. Fernandez J.A., Carballeira A. Evaluation of contamination, by different elements, in terrestrial mosses. Archives of environmental contamination and toxicology. 2001. Vol. 40. № 4. P. 461-468. DOI: 10.1007/s002440010198.

8. Opekunova M.G., Opekunov A.Y., Kukushkin S.Y., Ganul A.G. Background Contents of Heavy Metals in Soils and Bottom Sediments in the North of Western Siberia// Eurasian Soil Sc. 2019. Vol. 52. P. 380-395. DOI: 10.1134/ S106422931902011X.

9. Характеристики загрязняющих веществ из раздела «I для атмосферного воздуха» «Перечня загрязняющих веществ, в отношении которых применяются меры государственного регулирования в области охраны окружающей среды». Справочник. ФГБУ УралНИИ «Экология», 2017. $284 \mathrm{c}$.

Characteristics of pollutants from section «I. For atmospheric air " from «The list of pollutants in relation to which measures of state regulation in the field of environmental protection are applied», Handbook. FGBU UralNII «Ecology», 2017. 284 p. (in Russian).
10. Королева Ю.В. Биоиндикация атмосферных выпадений тяжелых металлов в Калининградской области: по мхам: дис. ... канд. геогр. наук: специальность 25.00.36 Геоэкология. Калининград, 2004. 157 с.

Koroleva Yu.V. Bioindication of heavy metals atmospheric deposition in the Kaliningrad region: by mosses: dissertation cand. ... geogr. nauk: speciality 25.00.36 Geoecology. Kaliningrad, 2004. 157 p. (in Russian).

11. Чертко Н.К. Геохимия ландшафта. Минск: БГУ, 2011. 303 c

Chertko N.K. Geochemistry of the landscapes. Minsk: BSU, 2011. 303 p. (in Russian).

12. Геохимия. Сост.: Марченко А.Г., Смоленский В.В. Санкт-Петербургский горный ин-т, СПб., 2006. 56 с.

Geochemistry. Content by: Marchenko A.G., Smolenskiy V.V. S-Petersburgh gornyi institute. SPb., 2006. 56 p. (in Russian).

13. Антипова О.С. Геоэкологическая оценка среды жизнедеятельности населения Беларуси: автореф. дис. ... канд. геогр. наук: специальность 25.03.13 Геоэкология. Минск, 2018. 23 c.

Antipova O.S. Geoecological assessment of the living environment of the population of Belarus: Avtoref. dis. ... cand. geogr. nauk. speciality 25.03.13 Geoecology. Minsk, 2018. 23 p. (in Russian).

14. Витченко А.Н., Антипова О.С. Геоэкологическая оценка среды жизнедеятельности населения Беларуси // Вестник Белорус. гос. ун-та. Серия 2: Химия, Биология, География. 2016. № 3. С. 138-143.

Vitchenko A.N., Antipova O.S. Geoecological assessment of the living environment of the population of Belarus // Journal of the Belarusian State University. Issue 2: Chemistry Biology Geography. 2016. № 3. P. 138-143 (in Russian).

15. Матковская О.Г. Типологизации территорий по уровню антропогенной нагрузки на атмосферный воздух // Экономика и управление. 2012. № 2. С. 79-86.

Matkovskaya O.G. Classification of territories by the level of anthropogenic load on a free air// Economics and Management. 2012. № 2. P. 79-86 (in Russian). 